\title{
A Study on Mechanical Properties of Short Kenaf Fiber Reinforced Polylactide (PLA) Composites*
}

\author{
Kohji SUZUKI** \\ ${ }^{* *}$ Chiba Institute of Technology, Department of Mechanical Science and Engineering, \\ 2-17-1 Tsudanuma, Narashino-shi, Chiba 275-0016, Japan \\ E-mail: kohji.suzuki@it-chiba.ac.jp
}

\begin{abstract}
In this study, bast fibers of kenaf (Hibiscus cannabinus L.), in the form of randomly dispersed short-fiber reinforcement, were loaded into poly(lactic acid) (PLA) or simply polylactide. Twin-bladed melt mixing followed by hot-pressing was chosen as the present composite molding with fiber weight fractions varied from $0 \mathrm{wt} \%$ (i.e. neat PLA) to $20 \mathrm{wt} \%$ by $5 \mathrm{wt} \%$ increment. From the optical microscopic surface images, kenaf fibers were found to evenly be dispersed in the present composites with random fiber orientations in the two-dimensional flat-wise directions. Tensile strength and strain at break of the composites were found to decrease as compared to those of neat PLA. On the other hand, the tensile moduli both at initial and at several stress levels up to the final breakage were found to be improved via kenaf fiber loading. Two-parameter Weibull plots in terms of tensile strength and SEM fractography of the fractured surfaces were also examined and complicated and multiple sources for the fracture initiation and propagation in the present composites were implied. Finally, flexural properties, Charpy impact toughness, plain strain fracture toughness and S-N curves for the present composites were also shown and then discussed to sustain some benefits of the kenaf fiber loading.
\end{abstract}

Key words: Green Composites, Kenaf, PLA, Polylactide, Mechanical Properties, Tensile Strength, Stiffness Retention, Weibull Analysis, Fractography, Impact Toughness, Facture Toughness, Fatigue

\section{Introduction}

It has been some time now since, as preparation for a future possible depletion of fossil fuel resources, not a few alternative materials of non-fossil-fuel origin have been tried out in various industrial scenes. These trends would have possibly been spurred, especially here in Japan, since the days after the Great East Japan Earthquake in 2011 and the continuing severe nuclear accidents, which certainly arouse serious discussions on the feasibility of a nation-wide shift towards new community-based forms of our energy supply system and industrial supply-chain. Among them, making an effective use of renewable on-site biomass resources might have a high degree of expectation for using them as industrial crude materials rather than for putting the full amount of them onto the power and energy sectors.

Against this background, biomass-derived plastics such as poly(lactic acid) (PLA), or simply polylactide, natural plant fibers such as kenaf (Hibiscus cannabinus L.) and structural composite materials wholly or partially constituted of them have recently been attracting much attention. Needless to say, such biomass-based raw materials and composites are non-petroleum, carbon-neutral, annually renewable, and, because of these advantages, they are gradually appearing in the open scenes of the industries as fairly

*Received 5 Sep., 2012 (No. 12-0354) [DOI: 10.1299/jmmp.7.439]

Copyright () 2013 by JSME 
"green" materials. Another thing besides this point is that such biomass resources are typically abundant as agricultural crop wastes particularly in developing countries such as those in Southern and Southeastern Asia, Africa, South America, which are becoming main battlefields of global manufacturing industries. Therefore, the so-called green composite technologies could be sorts of valuable trump cards in those emerging markets.

Several well-organized and comprehensive reviews on research and development activities, conducted in the 80 's and 90's, relevant to either or both of natural fibers and biodegradable polymers, as well as their composites, including combinations of natural fibers and conventional chemosynthetic polymers such as polypropylene (PP), were made, for example, by Bledzki, Reihmane and Gassan ${ }^{(1)}$, and then by Mohanty, Misra and their co-workers ${ }^{(2),(3)}$. Around and after the year 2000, Mohanty, Misra, Drzil and others ${ }^{(4)}$ outlined the general trends and guidelines of the natural fibers and biocomposites. Holbery and Houston made a survey of natural-fiber-reinforced chemosynthetic polymer composites in automotive applications ${ }^{(5)}$. On the other hand, Goda and Cao ${ }^{(6)}$ reviewed on the R \& D activities of "fully green" composites up to around the year of 2007. John and his colleagues also reviewed on the similar topics in the early 2000 's up to $2008^{(7),(8)}$.

When one focuses on a more specific case study, an assortment of poly(lactic acid) (PLA), or simply polylactide, and various natural fibers, most of which are ligno-cellulosic ones extracted from plant fibrous tissues, is found to be one of the most actively investigated candidates for "bio-" or "green-"composites ${ }^{(9)}$ since PLA itself has relatively favorable physical and mechanical properties for load-bearing structural components ${ }^{(10),(11)}$ and also has grown to be one of the most mass-produced biodegradable polymers in the world $^{(12)}$. PLA, or polylactide, is thermoplastic crystalline polymer which is bulk-produced through polymerizing the lactic acid monomers gathered via industrial glucose fermentation, and have fairly good macroscopic mechanical properties (e.g., static strength, modulus and so forth) for light-weight structural and casing components ${ }^{(10)}$. Neat PLA is, however, generally said to be brittle in nature, lacking static and/or impact fracture toughness especially in the case of high degree of crystallinity that will inherently be necessary for keeping its better heat resistance. This might be one of the major motivations for attempting to introduce some reinforcing fibers or fillers into this thermoplastic crystalline polymer system.

As for PLA's reinforcing counterparts in the present composite system, bast fibers from flax (Linum usitatissimum) ${ }^{(13)-(21)}$ and industrial hemp (Cannabis sativa L.) $^{(9),(22) \text {-(26) have }}$ been popular particularly in Europe, North America and Oceania because these two varieties have long been cultivated in those areas for their traditional apparel and fabric materials with good quality and mechanical properties. For instance, Oksman et al. ${ }^{(13)}$ reported several typical mechanical properties of flax fiber reinforced poly(lactic acid) composites manufactured using a twin-screw extruder and a compression molding press. Mathew et al. ${ }^{(14)}$ also studied on the crystallinity of PLA with a few cellulose-based reinforcements including flax fibers. Wong, Shanks and Hodzic ${ }^{(15)}$ investigated the static and dynamic tensile properties of poly(L-lactic acid)-flax composites along with their interlaminar fracture toughness evaluations, and further Shanks, Hodzic and Ridderhof ${ }^{(16)}$ studied on PLA with flax fibers modified by interstitial polymerization. Bodros et al. ${ }^{(17)}$ and Le Duigou et al. ${ }^{(18)-(20)}$ also studied fabrications and mechanical properties of flax/PLA composites. Bax and Müssig ${ }^{(21)}$ studied impact and mechanical properties of PLA/flax composites. Masirek et al. ${ }^{(22)}$, on the other hand, reported physical and mechanical properties of PLA/hemp composites. Graupner, Herrmann and Müssig (9) investigated mechanical characteristics of hemp-PLA composites. Islam et al. (23), (24) examined physico-mechanical properties of alkali-treated industrial hemp fibre reinforced PLA composites. More recently, Sawpan et al. ${ }^{(25),(26)}$ reported on the improvement of mechanical properties of chemically treated industrial hemp fibre reinforced polylactide (PLA) biocomposites. By the way, when one takes a quick glance at other reinforcing fiber plants 
for natural fiber/PLA composites, jute (Corchorus capsularis L.) ${ }^{(27)-(29)}$, abacá (Musa textilis Née) ${ }^{(30)}$ and coir (Cocos nucifera L.) ${ }^{(31)}$ from Southern and Southeastern Asia, ramie (Boehmeria nivea L.) $^{(32),(33)}$ and bamboo (Phyllostachys bambusoides) ${ }^{(34)-(36)}$ mainly from Eastern Asia, henequen (Agave fourcroydes Lem.) ${ }^{(37)}$ from Central and South America can also be found clearly reflecting the specialty of its own traditional textile industry for each of those areas. Graupner ${ }^{(38)}$ also studied mechanical properties of PLA composites reinforced with cotton (Gossypium hirsutum L.).

Since there isn't any specific species capable to produce "unusually-good" fibers which are extraordinarily superior to other natural plant fibers in terms of their chemical compositions and physical/mechanical properties, what is more important in screening the natural fibers for PLA composite products probably lies in other matters such as availability, harvesting and processing time and cost, revitalization of the rural economy and so forth. From this viewpoint, kenaf (Hibiscus cannabinus L.) ${ }^{(39),(40)}$ could be one of the most promising natural fiber crops because it grows fast almost anywhere except in the polar regions with good resistance to plant disease. It also has a proven past record as a potential non-wood raw material for the paper manufacturing industry ${ }^{(41),(42)}$, and experiences and know-how for its cultivation and harvesting have been accumulated ${ }^{(40)}$. Its anatomical morphology and mechanical properties were studied in detail by the present author with the aid of statistical data analysis methods ${ }^{(43),(44)}$, and its suitability for polymer composite reinforcements has been shown. Ramaswamy et al. ${ }^{(45)}$ developed kenaf nonwoven plate with polypropylene (PP) as binder, while Onishi et al. ${ }^{(46)}$ reported their kenaf-fiber-oriented construction boards with isocyanate resin as binder. Nishimura ${ }^{(47)}$ gave an outline of the manufacturing procedures of kenaf-PP boards for car components. Zampaloni et al. ${ }^{(48)}$ discussed on manufacturing problems and solutions of kenaf-PP composites. On the other hand, John et al. ${ }^{(49)}$ studied on effects of amphiphilic coupling agent of surface properties of kenaf-polypropylene composites. Shibata, Cao and Fukumoto ${ }^{(50)}$ made lightweight laminate composites from kenaf and PP fibers. More recently, Aji et al. ${ }^{(51)}$ reviewed research activities of kenaf fibers as polymeric composites reinforcement. Akil et al. ${ }^{(52)}$ also overviewed kenaf fiber reinforced composites. According to Arai ${ }^{(53)}$, in the year of 2011 , another new project for kenaf industrialization had been kicked off in Thailand.

To the best knowledge of the present author, one of the earliest attempts to use kenaf fibers for PLA composites was made by Nishino et al. ${ }^{(54),(55)}$ by employing their simple wet processing. In their works, kenaf bast fiber sheets like paper were immersed into PLLA (poly(L-lactic acid)) dioxane solution and then dried under vacuum to form kenaf sheet composites with PLLA as binder. They reported their composite sheets with $70 \%$ kenaf fibers had better mechanical properties when compared to pure PLA sheet. At roughly the same time, Serizawa, Inoue and Iji of NEC Corp. ${ }^{(56)}$ developed their kenaf-fiber-reinforced poly(lactic acid) (PLA) composites for the housing of electronic products by combining the melt-mixing and injection-molding methods. They reported that adding the short kenaf fibers greatly increased the heat resistance, modulus and impact strength of PLA. Pan et al. including the above-mentioned NEC researchers ${ }^{(57)}$ also reported on crystallization behaviors and mechanical properties of the short-kenaf-fiber PLA composites prepared with the similar injection-molding process described in ref.56. More recently Anuar et al. ${ }^{(58)}$ have studied on fabrication of PLA-kenaf biocomposites using intermeshing co-rotation twin-screw extruder and then injection molding. On the other hand, in 2005, the present author et al. ${ }^{(59)}$ molded PLA composites unidirectionally reinforced with long kenaf bast fibers. In that attempt of the present author et al., emulsion PLA was used. The same kind of idea of this composite manufacturing by using long kenaf fibers and emulsion PLA was also adopted by Ochi ${ }^{(60)}$, who, in addition to mechanical characterizations, investigated biodegradation behaviors of his kenaf/PLA composites.

For more strength-oriented kenaf/PLA composites, Ben et al. ${ }^{(61)}$ fabricated their green composite laminates by alternately stacking and then hot-pressing unidirectional kenaf yarn 
fabrics and PLA films. They also examined innovative ways for improving interfacial strength of their laminated composites. The similar compression molding technique using film stacking method for kenaf/PLA composites was also tried out by Huda et al. ${ }^{(62)}$, who also investigated the effect of kenaf surface treatments on the thermo-mechanical properties of their composites. Another approach for kenaf/PLA composite manufacturing was made by Graupner et al. ${ }^{(9),(38)}$ and by Lee et al. ${ }^{(63)}$, in which at the first step both the chopped kenaf and melt-spun PLA fibers were entangled together with a roller carding machine, next needle-punched to get non-woven composite preforms and then these kenaf/PLA preforms were compression-molded with hot-pressing machine. Lee et al. ${ }^{(63)}$ examined the effect of silane coupling agent on the mechanical properties of the composites by using their roller-carding process. They also reported on a prototype automotive interior headliner made of PLA/kenaf 50wt.\%. Cho et al. ${ }^{(37)}$ also used sheets of compounding of kenaf and melt-spun PLA fibers for their compression molding composite processing. This idea of kenaf/PLA compound (preform) might be promising in that relatively long kenaf reinforcing fibers will be uniformly dispersed within the composites, that fiber surface treatments can be easily and effectively carried out and also that larger products with complicated shape could be mass-produced. However a certain concern to be wiped away about this composite processing is that the mechanical properties of PLA sheets made from melt-spun PLA fibers, at least judging from the aforementioned existing literatures, seem to be considerably degraded as compared to those from PLA pellets.

One of the keys for successful kenaf/PLA composite manufacturing might be how to effectively utilize the existing molding techniques and apparatus while as much as possible avoiding kenaf fiber's damage and PLA degradation during the molding process. As one of the answers to this requirement, Osawa ${ }^{(64)}$, Avella et al. ${ }^{(65)}$ and Ogbomo et al. ${ }^{(66)}$ adopted the composite processing of melt mixing with a brabender-type mixer followed by compression-molding. One of the advantages of the present molding method over those that have already been reviewed in this chapter is that any melt-spun PLA fibers with degraded properties as used in the roller carding processes will not be used while larger and more complicated structural components can be manufactured with the existing compression molding equipments, which may not easily be achieved by using the conventional injection molding techniques. However, in order to further promote the present technique for kenaf/PLA composites, more and more molding trials and experimental results should be compiled with particular emphasis put on both completeness of test data and statistical treatments for quality assurance aspects toward their practical use in near future.

In the present paper, the composite preparation process of kenaf random short-fiber reinforced polylactide (PLA) using a twin-bladed brabender-type mixer followed by hot-pressing, which may be roughly similar to the one adopted by Osawa ${ }^{(64)}$, will be briefly described. Optical microscopic surface images of the composites will be examined for randomness of short-fiber dispersion. Essential mechanical properties such as tensile strength and strain at break will be obtained with fiber weight fractions varied up to $20 \mathrm{wt} \%$ by $5 \mathrm{wt} \%$ increment. In addition, the mechanical properties at the service load conditions, such as structural elastic stiffness (initial Young's modulus) and stiffness retention at any stress levels up to breakage will also be evaluated. To the author's best knowledge, attempts to evaluate such stiffness retention properties of kenaf/PLA composites are very rare and will be quite beneficial since for polymeric composite materials, which will not go through any severe ultimate loads like those in the plastic forming process of metals, these elastic properties might be treated as sorts of meaningful indices for structural healthiness. Furthermore, two-parameter Weibull statistical plots in terms of tensile strength will also be shown and discussed, which is certainly one of the neglected subjects for kenaf/PLA composites and hence should be investigated here since there is a possibility that any natural fiber reinforced composites may inherently be unavoidable from statistical scatter or uncertainty. For the fractured surfaces of the specimens, scanning electron microscope 
(SEM) images will be taken and then discussed. Finally, other practical mechanical properties, which have been neglected commonly in the precedent literatures on kenaf/PLA composites, such as flexural strength and modulus, Charpy impact toughness, plain strain fracture toughness and S-N curves for tension-tension cyclic loadings will also be obtained and then discussed here to sustain some benefits of the kenaf fiber loading into PLA.

\section{Base Materials and Composite Preparation}

\subsection{Base Materials}

Kenaf bast fibers used in the present study were harvested and processed in Indonesia originally for loading into polypropylene automotive interior components as reinforcing fillers ${ }^{(47)}$. In Fig.1(a), the present kenaf technical fibers were shown. Almost any kinds of plant fibers commonly take a form of bundles, so-called technical fibers, which consist of several plant cells having thick and stiff secondary cell walls ${ }^{(43),(44),(67) \text { - (69) }}$. The fibers were cut into approximately $5 \mathrm{~mm}$ in length by putting them through a general purpose paper shredder to loosen the fiber bundles for their easy mixing with the melted PLA in a mixer. The mean and coefficient of variation $(\mathrm{CV})$ of the monofilament tensile strength of the kenaf technical fibers were experimentally found to be $309 \mathrm{MPa}$ and $43.3 \%$, respectively ${ }^{(43)}$. Tensile stiffness of kenaf fibers may range approximately from $20 \mathrm{GPa}$ to $40 \mathrm{GPa}$. On the other hand, in Fig.1(b), polylactide (poly(L-lactic acid) (PLLA), REDOVE101, Zhejiang Hisun Biomaterials Co., Ltd.) are shown. The present thermoplastic resin pellets (molecular weight: 94,000 , melting point: $145^{\circ} \mathrm{C}$ as reported by the manufacturer) are originally designed for sheet extrusion applications.

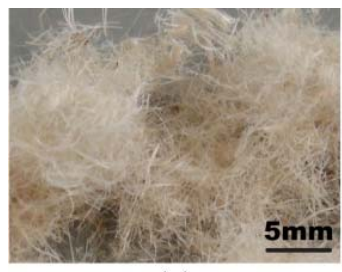

(a)

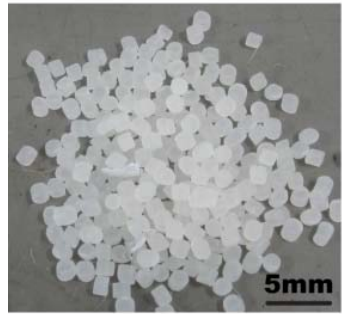

(b)

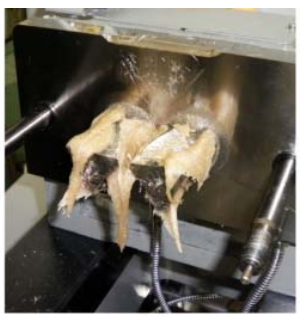

(c)

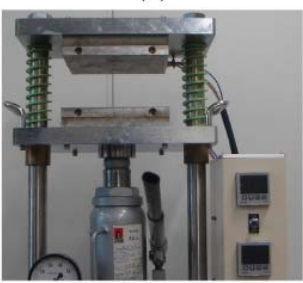

(d)

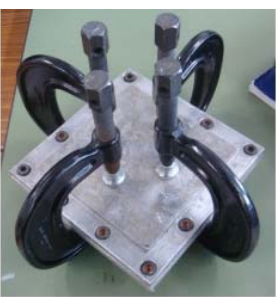

(e)

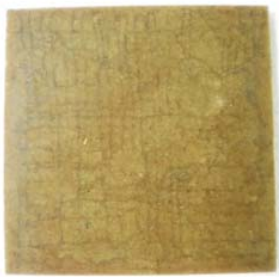

(f)

Fig. 1 Base materials; (a) kenaf bast fibers and (b) poly(lactic acid) (PLA) or simply polylactide, and the present composite processing; (c) melt-mixing with the brabender-type mixer,

(d) hot-press machine, (e) picture frame mold, and (f) the composite plate removed from the mold.

\subsection{Composite Molding}

As shown in Fig.1(c), polylactide (PLA) pellets and kenaf fibers (approx. $5 \mathrm{~mm}$ long technical fibers), dried at $105^{\circ} \mathrm{C}$ for 5 hours on ahead, were kneaded with a twin-bladed brabender-type melt mixing machine (Labo Plastomill 10C100 R60, Toyo Seiki Seisakusho, Ltd.) for about 5 minutes to make a hot bulk of kenaf and polylactide composite mixture. Figure 2(a) shows the typical profiles of the chamber temperature and the applied torque during the present melt mixing. The weight fraction of the fibers to the kenaf/PLA composites was varied from $0 \mathrm{wt} \%$ (that is, neat PLA) to $20 \mathrm{wt} \%$ by $5 \mathrm{wt} \%$ increment. Any chemical or physical fiber surface treatment was not applied throughout the present composite processing for future references.

As shown in Fig.1(d), the mixtures were next hot-pressed between the two aluminum- 
alloy picture-flame molding dies $\left(140 \times 140 \mathrm{~mm}^{2}\right.$ and $5 \mathrm{~mm}$ thick), with $1 \mathrm{MPa}$ pressure applied at $180^{\circ} \mathrm{C}$ for about 5 minutes. Each time before the hot-pressing, the surface of mold plates was polished with fine sandpaper and wiped with acetone, and then mold wax and polyvinyl alcohol (PVA) were applied on the plate surface aiming for smooth release of molded composites from the die. After that, the die was taken out from the hot-press machine and then it was tightened up with four C-cramps and air-cooled for 5 minutes as shown in Fig.1(e), which reduced the temperature of the composites down to approximately $140^{\circ} \mathrm{C}$. Finally, it was rapidly quenched down to the room temperature by soaking it into cold running water for another 5 minutes and then the molded sheet was removed from the picture flame die with hydraulic force. The typical temperature profile during hot-pressing is shown in Fig.2(b). One of the reasons why rapid water quenching was applied in the present composite processing is for making degree of crystallinity of PLA almost the same for all of the present molded sheets of neat PLA and kenaf/PLA composites. It is noted that PLA is in nearly amorphous state when the present rapid quenching is applied. There wasn't any noticeable evidence of degradation of the molded composites through exposing water possibly because the exposure time was very short. In Fig.1(f), the molded composite plate (one of the $20 \mathrm{wt} \%$ cases) is shown. The thickness of the present plates was designed to become approximately $4 \mathrm{~mm}$.

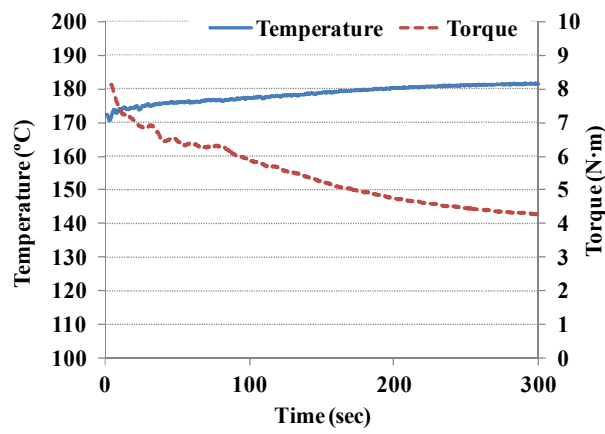

(a) during melt-mixing

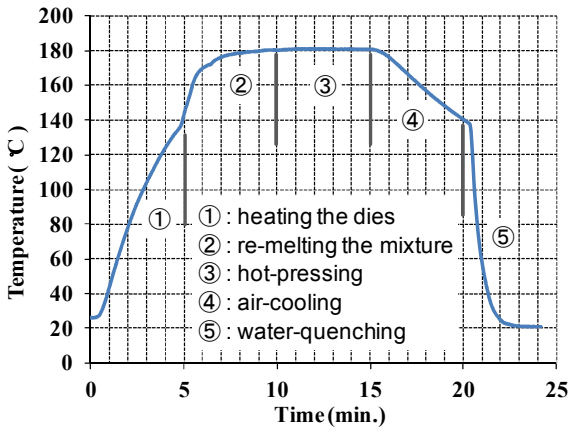

(b) during hot-pressing

Fig. 2 The typical composite processing profiles.

\section{Experimental Procedures}

\subsection{Fiber Measurement}

The degree of kenaf short-fibers' dispersion inside the present composites was firstly quantified based on optical images of the plate surfaces taken by the optical digital microscope (DS-3UXL-III, Micro Square Co., Ltd.). From this image analysis, fiber orientation angle, $\alpha\left[^{\circ}\right]$, and fiber length, $l[\mathrm{~mm}]$, and diameter, $d[\mu \mathrm{m}]$, for each fiber were measured, as schematically shown in Fig.3, for constructing their statistical distributions which can be served as an index of fiber dispersion randomness.

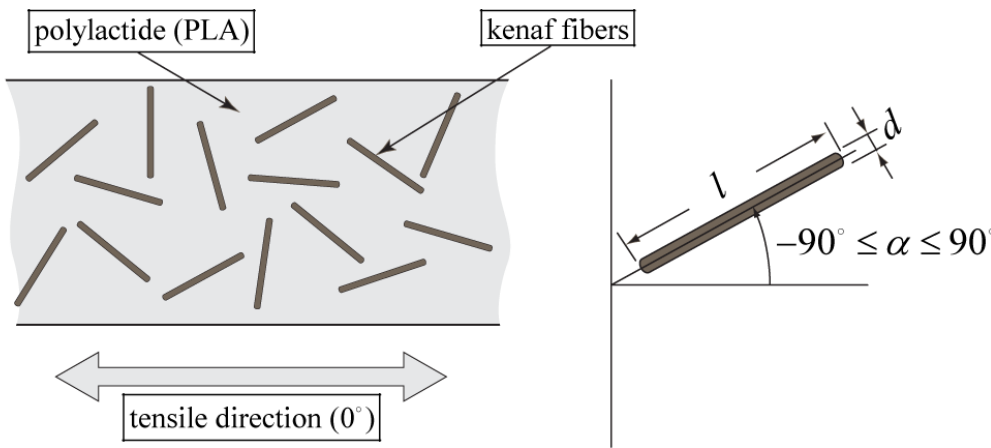

Fig. 3 Measurement of fiber orientation angle, $\alpha$, and fiber geometries (length, $l$, and diameter, $d$ ). 
From the orientation angle $\alpha$, the orientation parameter $f_{p}$ will be evaluated as follows;

$$
f_{p}=2\left\langle\cos ^{2} \alpha\right\rangle-1, \text { where }\left\langle\cos ^{2} \alpha\right\rangle=\sum_{j} \frac{N\left(\alpha_{j}\right)}{N_{\text {total }}} \cos ^{2} \alpha_{j}
$$

in which $N\left(\alpha_{j}\right)$ is the number of samples of $\alpha_{j}$ and $N_{\text {total }}$ is the total number of the samples. When the parameter $f_{p}$ is found to be zero, the composite has complete random fiber orientation in the two-dimensional directions.

\subsection{Tensile Test}

Quasi-static tensile tests, according to JIS K 7164 (equivalent to ISO 527-4), were carried out to the present composites. As shown in Fig.4(a), at least eight dog-bone specimens $4 \mathrm{~mm}$ thick and $8 \mathrm{~mm}$ wide for each case of the neat PLA and the kenaf/PLA composites were cut out from the molded plates of Fig.1(f) with a water-jet machining. The specimens were then dried more than 24 hours in a vacuum desiccator and an instron-type screw-driven universal tester (5kN capacity, Tokyo Testing Machine Inc.) was used for the present tensile test with cross-head speed of $1 \mathrm{~mm} /$ minute. Elongations up to breakage for the gauge length of $40 \mathrm{~mm}$ were measured with the image video extensometer. Quasi-static tensile strength, strain at break, initial tensile modulus (evaluated over $0.05 \%-0.15 \%$ strain) and stiffness retentions against the applied tensile stress (as illustrated in Fig.4(b)) were post-calculated from nominal stress - nominal strain curves.

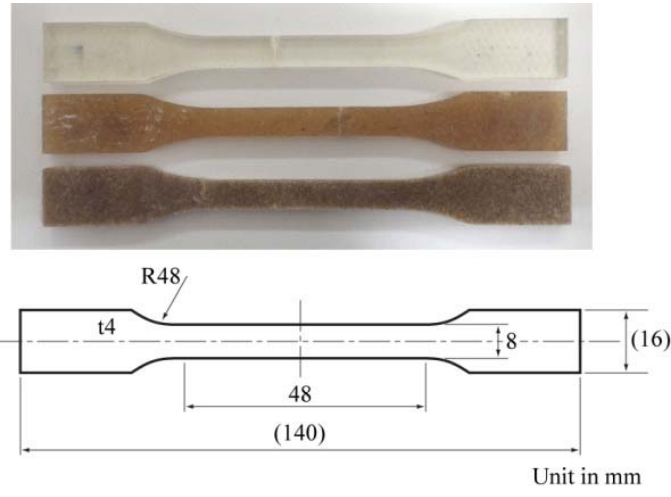

(a) Tensile test specimens

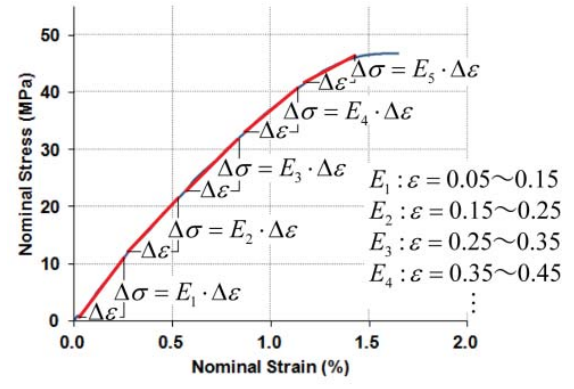

(b) Stiffness retention measurement

Fig. 4 Tensile test.

In addition to the above mentioned fundamental tensile properties, two-parameter Weibull plotting and parameter estimations in terms of tensile strength were conducted. The Weibull distribution function $F(\sigma ; L)$ is as follows;

$$
F(\sigma ; L)=1-\exp \left[-\left(\frac{L}{L_{0}}\right) \cdot\left(\frac{\sigma}{\sigma_{0}}\right)^{m}\right]
$$

where $F$ is the cumulative distribution function in terms of the tensile strength, $\sigma$. The parameters $m$ and $\sigma_{0}$ are respectively termed as shape and scale parameters. From the plots, statistical Weibull characteristic parameters (shape parameter, $m$, and scale parameters, $\sigma_{0}$, as in Eq.(2)) can be respectively estimated using the linear regression fitting.

\subsection{Fractured Surface Examination}

The fractured surface of tensile specimens with different fiber weight fractions were examined using a scanning electron microscope (SEM) (Hitachi Corp., TM1000).

\subsection{Other Practical Mechanical Properties Tests}

Quasi-static three point bending tests were conducted to the present composites for their flexural properties. A Charpy impact tester (Model DG-C, Toyo Seiki Seisakusho) was used 
for the impact toughness properties. On the other hand, according to ASTM D5045, three-point bend specimens with a single-edge-notch pre-crack were prepared and plain-strain fracture toughness $K_{\mathrm{IC}}$ was obtained by using the $J$-R curve method, detailed description of which can be found, for example, in ASTM D6068. In addition, S-N curves under tension-tension (stress ratio $R=0.1$ ) cyclic loads will also be obtained.

\section{Results and Discussion}

\subsection{Fiber Dispersion Randomness}

In Fig.5(a) and (b), optical microscopic surface images of the present composite (in $20 \mathrm{wt} \%$ case) in the two-dimensional flat-wise (in-plane) directions and in the edge-wise direction are respectively shown. From these images in the two different directions, it is found that kenaf fibers are two-dimensionally dispersed in the flat-wise (in-plane) directions and in the edge-wise direction they are horizontally aligned due to the applied pressure during the hot-press processing.

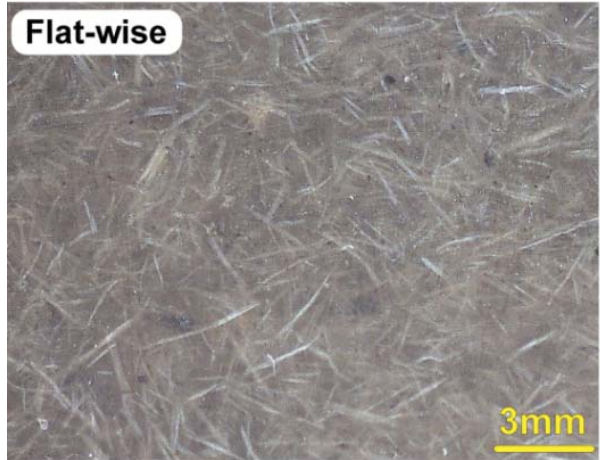

(a)
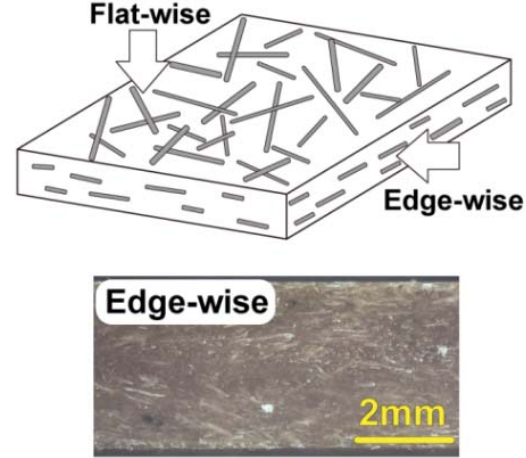

(b)

Fig. 5 Typical optical microscope images of the present composites;

(a) in the two-dimensional flat-wise directions and (b) in the edge-wise direction.

Figure 6 shows typical statistical distribution (histogram) of the fiber orientation angle $\alpha$ in the flat-wise directions in a kenaf/PLA composite sample (5wt\%). An almost uniform distribution in terms of the fiber orientation angle in these directions can be seen in the graph. The orientation parameter (Eq.(1)) $f_{p}$ is calculated to be 0.0487 , which also shows that the reinforcing kenaf short-fibers in the present composites are randomly dispersed in the two-dimensional flat-wise directions. In Fig.7(a) and (b), statistical distributions (histograms) of the fiber length and diameter are respectively shown. The mean and coefficient of variation of the present samples were $1.17 \mathrm{~mm}$ and $42.6 \%$ for the fiber length shown in Fig.7(a), and $62.9 \mu \mathrm{m}$ and $33.2 \%$ for the fiber diameter shown in Fig.7(b). It will be worth noting that the fiber length and diameter after the composite processing were found to become relatively smaller than those of the original technical fibers before the processing. This is because, during the present melt mixing process, the kenaf technical

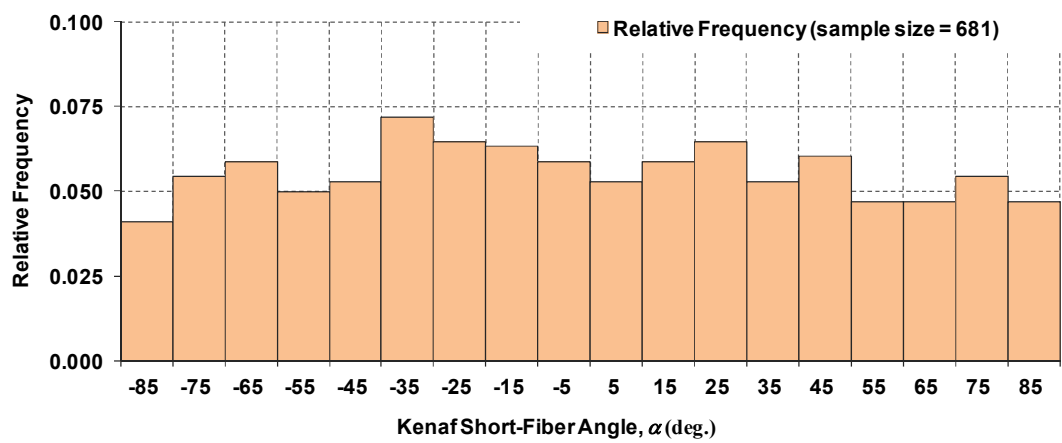

Fig. 6 Statistical distribution (histogram) of the fiber orientation angle, $\alpha$. 


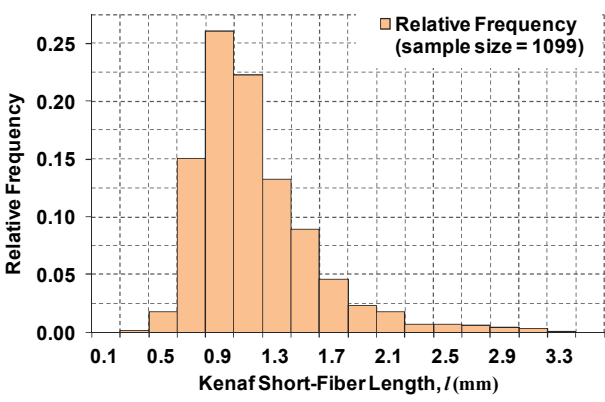

(a) Fiber length, $l$.

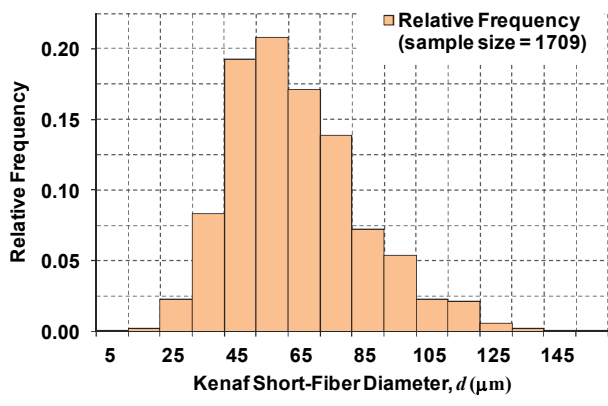

(b) Fiber diameter, $d$.

Fig. 7 Statistical distributions (histograms) of the fiber geometries; ((a) length, $l$, and (b) diameters, $d$ ).

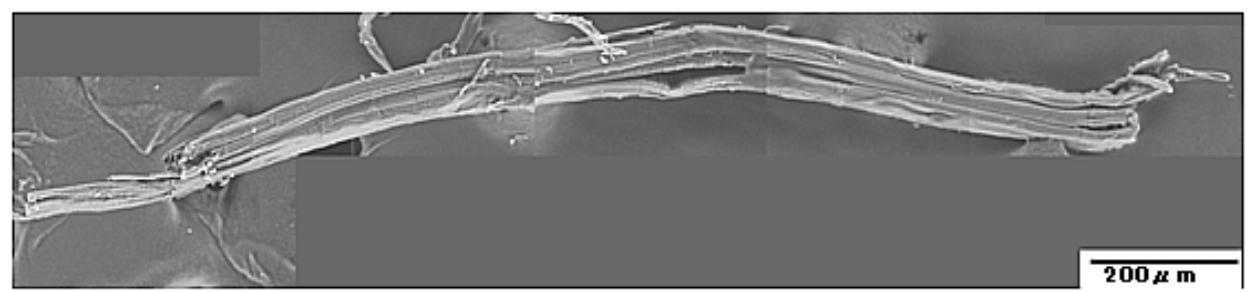

Fig. 8 A kenaf short fiber after molding typically observed in the present composites.

fibers, which were made up of elementally plant cells, were exposed to heat and mechanical shear force so that more or less fiber separations must have occurred as shown in Fig.8.

\subsection{Tensile Properties}

Figures 9(a)-(d) show the nominal stress - nominal strain curves obtained from the tensile tests for the neat polylactide (PLA) and the kenaf/PLA composites with different fiber weight fractions. The present stress - strain curves of PLA and kenaf/PLA composites exhibit a typical brittle nature of amorphous thermo-plastics and their composites. It is also apparent that kenaf fibers generally make PLA composites stiffer and their breaking points

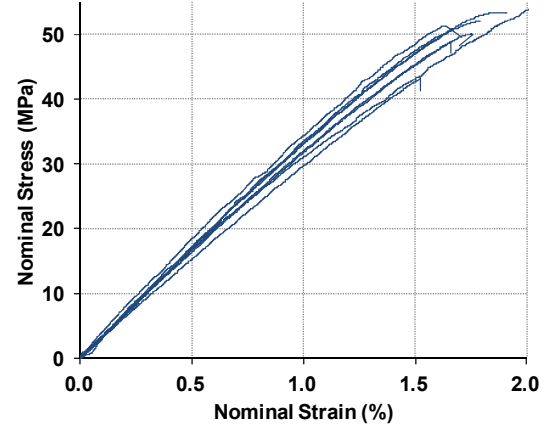

(a) $0 \mathrm{wt} \%$ (neat PLA)

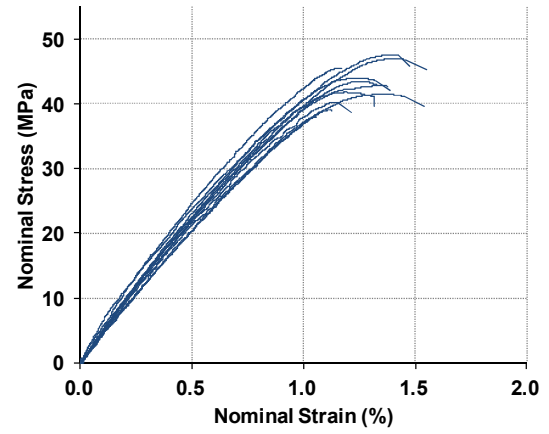

(c) $10 \mathrm{wt} \%$

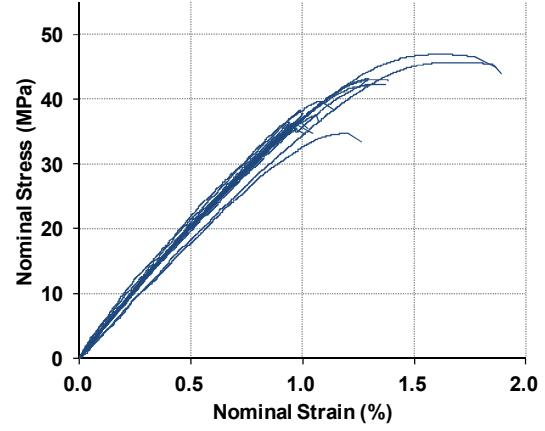

(b) $5 \mathrm{wt} \%$

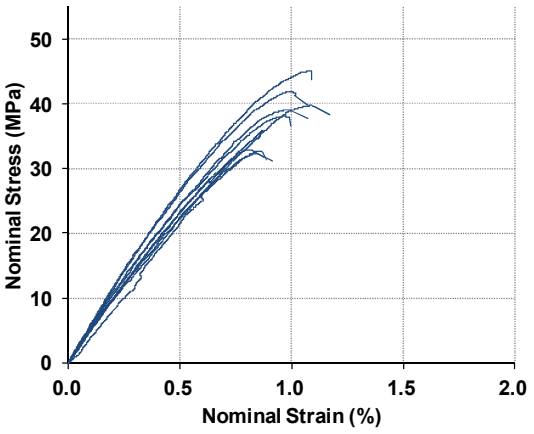

(d) $20 \mathrm{wt} \%$

Fig. 9 Nominal stress - strain curves of tensile tests 
slightly faster as compared to the neat resin. As for piece-to-piece variations for each fiber weight fraction, less fiber fraction cases such as $5 \mathrm{wt} \%$ seem to show slightly greater variations in terms of the shape, slope and breaking point of the stress - strain curves.

Figures 10 and 11 respectively show variations against kenaf weight fractions in terms of tensile strength and strain at break. The error bars in the graphs indicate the standard deviation. The tensile strength shown in Fig.10 was evaluated as a breaking force per cross-sectional area. Generally speaking, any benefit of kenaf fiber loading into the PLA in terms of the tensile strength was not found when compared to those of neat PLA, which can also be predicted from the stress - strain curves in Fig.9(a)-(d). This is probably because the interfacial bonding of the present composites may be relatively weak and fiber length, which might have been decreased because of fiber separations during the melt mixing as discussed in the previous section, may not be sufficiently large to efficiently utilize the axial stiffness and strength of the kenaf fibers especially at the very final stage of break.

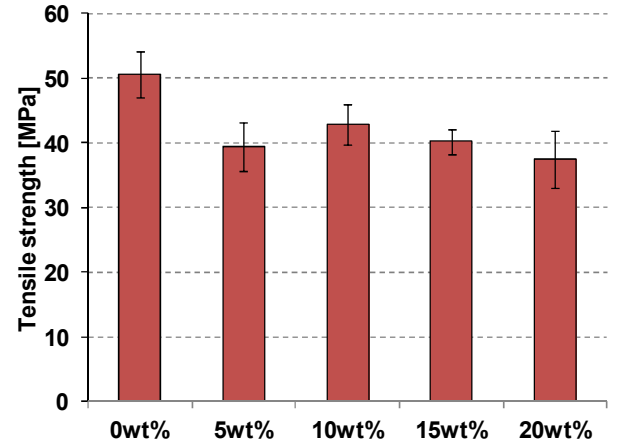

Fig. 10 Tensile strength.

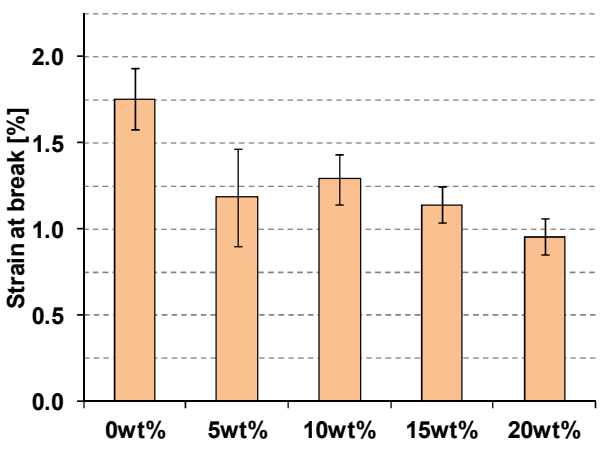

Fig. 11 Tensile strain at break.

The initial tensile moduli shown in Fig.12, on the other hand, were obtained as a slope of the stress - strain curves. The strain range that was used for the slope calculation was from $0.05 \%$ to $0.15 \%$. It is shown that the initial tensile modulus tended to increase by increasing the reinforcing kenaf fiber weight fraction. As for structural stiffness retention trends shown in Fig.13, all cases of the weight fraction of kenaf/PLA composites keeps their stiffness improvement up to a tensile stress level of approximately 30 to $35 \mathrm{MPa}$. These results in terms of the structural stiffness retention imply that kenaf/PLA composites exhibit better performance in low to medium stress levels possibly because some of the interfacial bonding between fibers and matrix are still working at those stress levels.

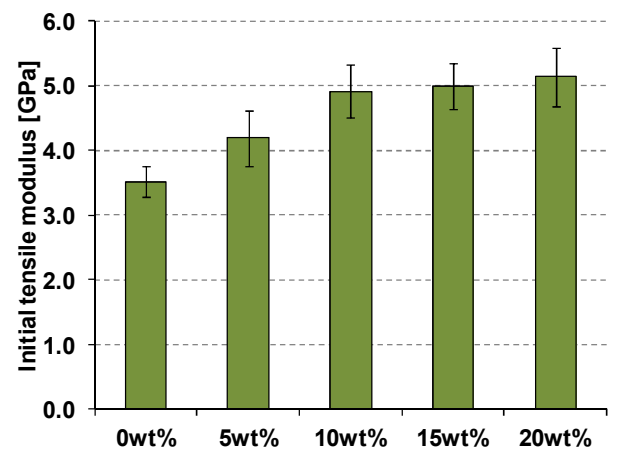

Fig. 12 Initial tensile modulus.

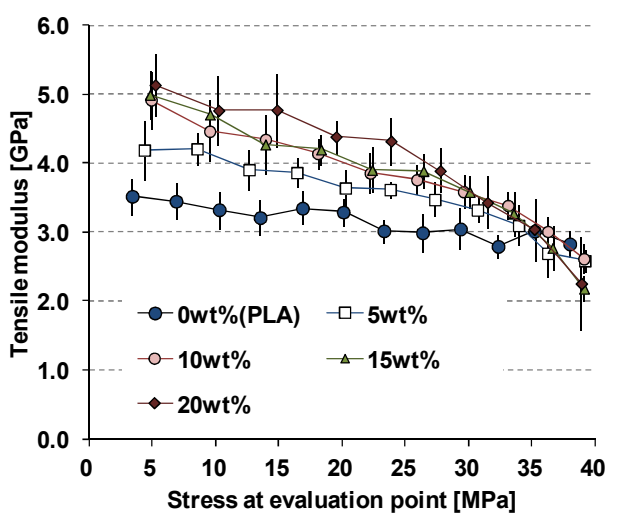

Fig. 13 Stiffness retentions.

In Fig.14, two-parameter Weibull plots in terms of tensile strength were shown. It was found that the present composite generally exhibit bimodal strength distributions with a combination of the stronger and more largely variable data and the weaker and less variable ones. The plot of neat polylactide strength, on the other hand, may be described with an 
unimodal distribution. In Table 1, Weibull parameters estimated by applying the least square fitting of Eq.(2) to the Weibull plots in Fig. 14 were shown. According to the present bimodal nature of the composite strength, the plots of the composites were separated into the higher and the lower data and then the parameter estimations were separately applied to each of those two data regions. As can be seen in the last column of the table, every determination coefficient, $r^{2}$, of regression for the least square fitting is well above 0.95 showing the reliability of the present parameter estimations. The bimodal distribution parameters probably reflect complicated and multiple sources for the fracture initiation and propagation up to breakage occurring in the present composites.

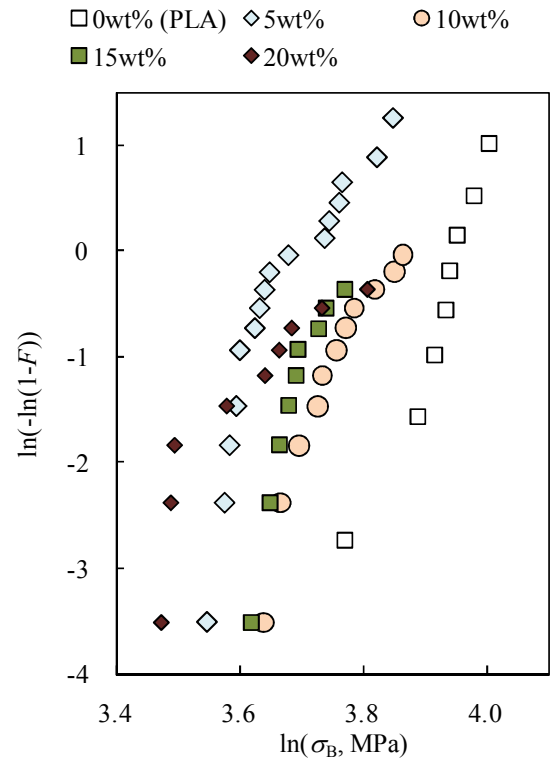

Fig. 14 Weibull plots in terms of tensile strength.

Table 1 Weibull parameters estimations for tensile strength.

\begin{tabular}{|c|c|c|c|c|c|c|c|}
\hline \multirow{2}{*}{$\begin{array}{l}\text { kenaf fiber } \\
\text { weight } \\
\text { fraction }\end{array}$} & \multirow[b]{2}{*}{$\begin{array}{c}\text { sample size } \\
N\end{array}$} & \multirow{2}{*}{$\begin{array}{c}\text { sample mean } \\
\sigma_{\mathrm{B} \text { mean }} \\
{[\mathrm{MPa}]}\end{array}$} & \multirow{2}{*}{$\begin{array}{c}\text { coefficient of } \\
\text { variation (\%) } \\
\quad C V_{\sigma \mathrm{B}} \\
\end{array}$} & \multicolumn{4}{|c|}{ estimation of the Weibull parameters in terms of $\sigma_{\mathrm{B}}$} \\
\hline & & & & data range & $m$ & $\begin{array}{c}\sigma_{0}, \mathrm{MPa} \\
\left(L_{0}=L=40 \mathrm{~mm}\right)\end{array}$ & $\begin{array}{c}r^{2} \text { of } \\
\text { regression }\end{array}$ \\
\hline $0 \mathrm{wt} \%$ & 8 & 50.58 & 6.85 & all 8 data & 16.48 & 52.16 & 0.971 \\
\hline \multirow{2}{*}{$5 \mathrm{wt} \%$} & \multirow{2}{*}{17} & \multirow{2}{*}{39.43} & \multirow{2}{*}{9.42} & higher 8 data & 7.153 & 40.09 & 0.968 \\
\hline & & & & lower 9 data & 38.32 & 37.88 & 0.970 \\
\hline \multirow{2}{*}{$10 \mathrm{wt} \%$} & \multirow{2}{*}{11} & \multirow{2}{*}{42.80} & \multirow{2}{*}{7.27} & higher 7 data & 8.216 & 47.75 & 0.982 \\
\hline & & & & lower 4 data & 22.34 & 43.95 & 0.955 \\
\hline \multirow{2}{*}{$15 \mathrm{wt} \%$} & \multirow{2}{*}{9} & \multirow{2}{*}{40.18} & \multirow{2}{*}{4.73} & higher 4 data & 7.671 & 45.45 & 0.981 \\
\hline & & & & lower 5 data & 32.42 & 41.44 & 0.993 \\
\hline \multirow{2}{*}{$20 \mathrm{wt} \%$} & \multirow[b]{2}{*}{9} & \multirow{2}{*}{37.48} & \multirow{2}{*}{11.85} & higher 6 data & 5.033 & 47.33 & 0.968 \\
\hline & & & & lower 3 data & 76.92 & 33.71 & 0.999 \\
\hline
\end{tabular}

\subsection{Fractured Surfaces}

In Fig.15(a)-(d), typical SEM micrographs of fractured surface of the tensile specimens (0wt\%(PLA) and 5-20wt\%) are picked up and shown. It is clearly seen in Fig.15(a) and (b) that the polylactide matrix breaks under static tension showing a typical brittle pattern with smooth and flat surfaces. On the other hand, although a few broken fibers can also be found on the surface of the composites as shown in Fig.15(b)-(d), there can be seen numerous kenaf fibers sticking out and their counter-part open holes (indicated by arrows), which had obviously been generated through pulling out the embedded fibers from the matrix during the fracture occurrence. These fractured surfaces observed here imply that, if ultimate strength at break is to be increased, either or both of the fiber/matrix bonding strength (interfacial shear strength) and the fiber length should be larger.

\subsection{Flexural Properties, Impact and Fracture Toughness and Fatigue Properties}

Figures 16 and 17 respectively show variations of flexural strength and initial flexural modulus against kenaf fiber weight fraction. Basically the same tendencies as those of tensile tests in Fig. 10 and 12 can be observed. However, in this case of three point bending test, both of tensile and compressive bending stresses occur in the specimens and more practical responses against more realistic flexural loading conditions can be seen.

Charpy impact toughness in Fig.18 and plain-strain fracture toughness in Fig.19 for the present composites were found to be relatively improved through kenaf fiber loading. This is probably because fairly large amount of energy dissipations along the frictional slippage 


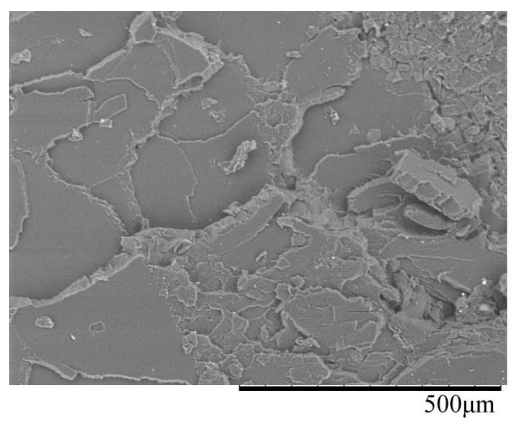

(a) $0 w t \%(P L A)$

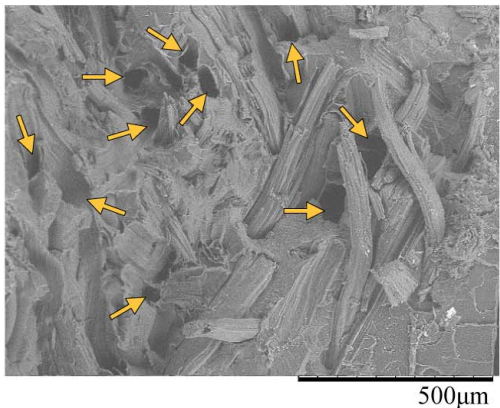

(c) $10 \mathrm{wt} \%$

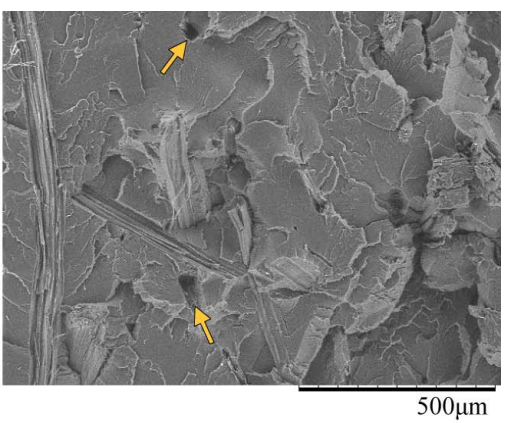

(b) $5 \mathrm{wt} \%$

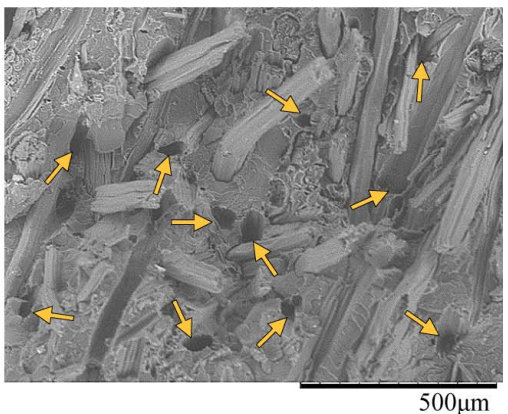

(d) $20 \mathrm{wt} \%$

Fig. 15 Fracture surfaces; (a) neat PLA $(0 \mathrm{wt} \%)$ and (b)-(d) kenaf/PLA composites (5-20wt\%).

at the fiber-matrix interfaces were induced during their fracture process. It is also noted that, in terms of impact/fracture toughness, $10 \mathrm{wt} \% \mathrm{kenaf} / \mathrm{PLA}$ achieved the saturated values. This might imply existence of an optimum fiber content, and should be further examined.

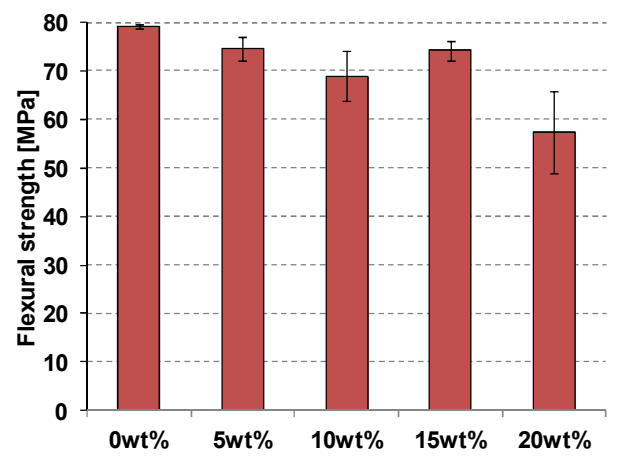

Fig. 16 Flexural strength.

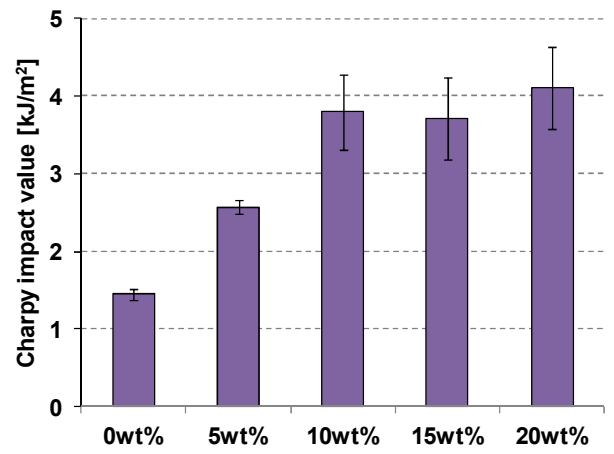

Fig. 18 Charpy impact toughness.

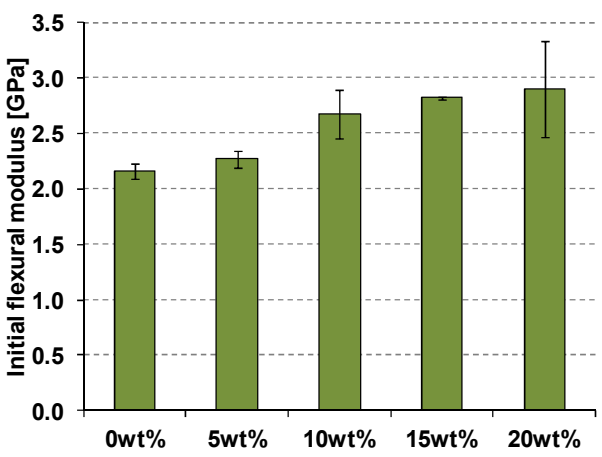

Fig. 17 Initial flexural modulus.

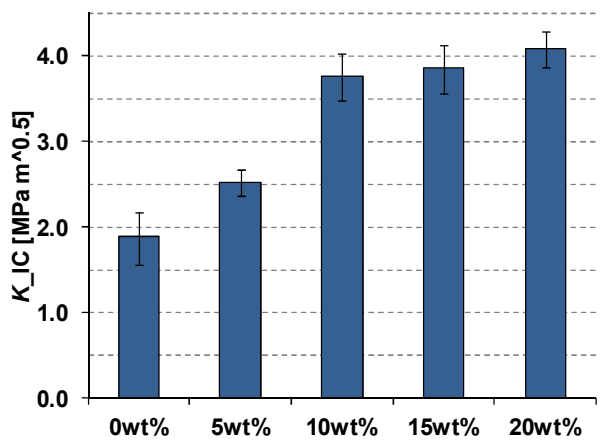

Fig. 19 Plain-strain fracture toughness.

Finally, in Fig.20, S-N plots for tension-tension $(R=0.1) 2.5 \mathrm{~Hz}$ cyclic loadings are shown. Although, at the static loading (i.e. $N=1)$, strength of neat PLA $(0 \mathrm{wt} \%)$ is the highest, there is a tendency that the regression line of S-N plot for neat PLA (0wt\%) 
declines at the fastest pace. This is possibly because neat PLA is inherently so brittle that, once cracks or flaws initiate in it, they will rapidly grow without any crack-arresting obstacles. On the other hand, kenaf/PLA composites generally can be said to be more resistible to low stress cyclic loadings since at the low level of stress the interfaces between kenaf fibers and PLA matrix are kept in good conditions.

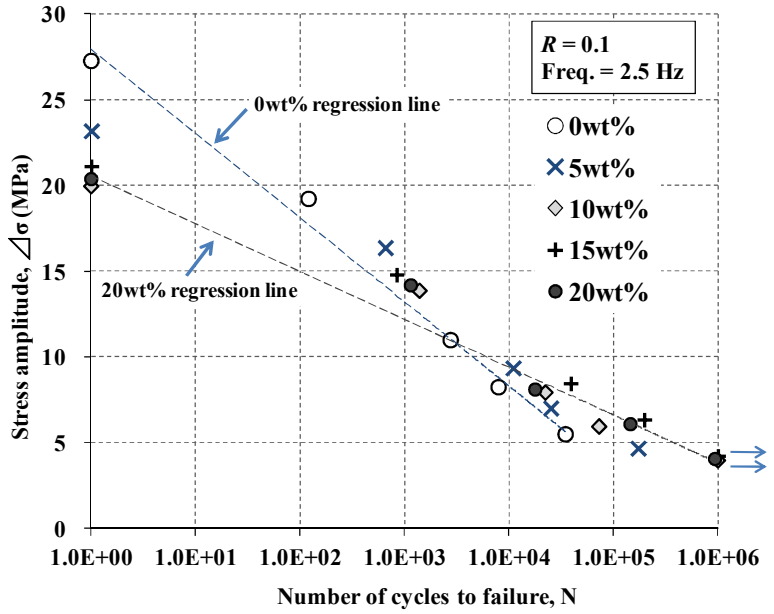

Fig. 20 S-N curves of tension-tension $(R=0.1)$ cyclic loadings.

\section{Conclusions}

In this study, neat polylactide (PLA) and randomly dispersed kenaf short-fiber PLA composites with several fiber weight fractions were molded through a twin-bladed melt mixing followed by hot-pressing. From the tensile test results, little benefit of kenaf fiber loading into the polylactide in terms of the tensile strength was found when compared to those of neat polylactide. This is probably because the interfacial bonding of the present composites may be relatively weak and fiber length that might be reduced during melt mixing process may be not sufficiently large to efficiently utilize the fiber strength especially at the final stage of break. The tensile moduli both at initial and at several stress levels up to the final breakage, on the other hand, were found to be improved via kenaf fiber loading. Two-parameter Weibull plotting in terms of tensile strength and SEM fractography for the fractured surfaces were also examined and complicated and multiple sources for the fracture initiation and propagation in the present composites were implied. Finally, flexural properties, impact toughness, fracture toughness and S-N curves for the composites were also examined and then discussed to show some benefits of the kenaf fiber loading.

\section{Acknowledgment}

The present author is deeply grateful to the former graduate and undergraduate students of Chiba Institute of Technology for all their help and support during his conducting the present study. Especially he is obliged to Mr. M. Misawa and Mr. A. Kikuchi for all their dedicated assistance on his composite molding and materials tests.

\section{References}

(1) Bledzki, A.K., Reihmane, S. and Gassan, J., Properties and modification methods for vegetable fibers for natural fiber composites, Journal of Applied Polymer Science, Vol.59, (1996), pp.1329-1336.

(2) Mohanty, A.K., Misra, M. and Hinrichsen, G., Biofibres, biodegradable polymers and biocomposites: An overview, Macromolecular Materials and Engineering, Vols.276/277, (2000), pp.1-24.

(3) Mohanty, A.K., Misra, M. and Drzal, L.T., Surface modifications of natural fibers and performance of the resulting biocomposites: An overview, Composite Interfaces, Vol.8, (2001), pp.313-343.

(4) Mohanty, A.K., Misra, M., Drzal, L.T., Selke, S.E., Harte, B.R. and Hinrichsen, G., Natural fibers, biopolymers and biocomposites: An introduction, in Mohanty, A.K., Misra, M. and Drzal, L.T., editors. Natural fibers, biopolymers and biocomposites, Boca Raton, CRC Press, (2005).

(5) Holbery, J. and Houston, D., Natural-fiber-reinforced polymer composites in automotive applications, JOM, Vol.58, (2006), pp.80-86.

(6) Goda, K. and Cao, Y., Research and development of fully green composites reinforced with 
natural fibers, Journal of Solid Mechanics and Materials Engineering, Vol.1, No.9, (2007), pp.173-184.

(7) John, M.J. and Thomas, S., Biofibres and biocomposites, Carbohydrate Polymers, Vol.71, (2008), pp.343-364.

(8) John, M.J. and Anandjiwala, R.D., Recent developments in chemical modification and characterization of natural fiber-reinforced composites, Polymer Composites, Vol.29, (2008), pp.187-207.

(9) Graupner, N., Herrmann, A.S. and Müssig, J., Natural and man-made cellulose fibre-reinforced poly(lactic acid)(PLA) composites: An overview about mechanical characteristics and application areas, Composites: Part A, Vol.40, (2009), pp.810-821.

(10) Lim, L.-T., Auras, R. and Rubino, M., Processing technologies for poly(lactic acid), Progress in Polymer Science, Vol.33, (2008), pp.820-852.

(11) Gupta, B., Revagade, N. and Hilborn, J., Poly(lactic acid) fiber: An overview, Progress in Polymer Science, Vol.32, (2007), pp.455-482.

(12) Lunt, J., Large-scale production, properties and commercial applications of polylactic acid polymers, Polymer Degradation and Stability, Vol.59, (1998), pp.145-152.

(13) Oksman, K., Skrifvars, M. and Selin, J.-F., Natural fibres as reinforcement in polylactic acid (PLA) composites, Composites Science and Technology, Vol.63, (2003), pp.1317-1324.

(14) Mathew, A.P., Oksman, K. and Sain, M., The effect of morphology and chemical characteristics of cellulose reinforcements on the crystallinity of polylactic acid, Journal of Applied Polymer Science, Vol.101, (2006), pp.300-310.

(15) Wong, S., Shanks, R.A. and Hodzic, A., Mechanical behavior and fracture toughness of poly(L-lactic acid)-natural fiber composites modified with hyperbranched polymers, Macromolecular Materials and Engineering, Vol.289, (2004), pp.447-456.

(16) Shanks, R.A., Hodzic, A. and Ridderhof, D., Composites of poly(lactic acid) with flax fibers modified by interstitial polymerization, Journal of Applied Polymer Science, Vol.99, (2006), pp.2305-2313.

(17) Bodros, E., Pillin, I., Montrelay, N. and Baley, C., Could biopolymers reinforced by randomly scattered flax fibre be used in structural applications?, Composites Science and Technology, Vol.67, (2007), pp.462-470.

(18) Le Duigou, A., Pillin, I., Bourmaud, A., Davies, P. and Baley, C., Effect of recycling on mechanical behaviour of biocompostable flax/poly(L-lactide) composites, Composites: Part A, Vol.39, (2008), pp.1471-1478.

(19) Le Duigou, A., Davies, P. and Baley, C., Interfacial bonding of flax/poly(L-lactide) bio-composites, Composites Science and Technology, Vol.70, (2010), pp.231-239.

(20) Le Duigou, A., Davies, P. and Baley, C., Macroscopic analysis of interfacial properties of flax/PLLA biocomposites, Composites Science and Technology, Vol.70, (2010), pp.1612-1620.

(21) Bax, B. and Müssig, J., Impact and tensile properties of PLA/Cordenka and PLA/flax composites, Composites Science and Technology, Vol.68, (2008), pp.1601-1607.

(22) Masirek, R., Kulinski, Z., Chionna, D., Piorkowska, E. and Pracella, M., Composites of poly(L-lactide) with hemp fibers: morphology and thermal and mechanical properties, Journal of Applied Polymer Science, Vol.105, (2007), pp.255-268.

(23) Islam, M.S., Pickering, K.L. and Foreman, N.J., Influence of alkali treatment on the interfacial and physico-mechanical properties of industrial hemp fibre reinforced polylactic acid composites, Composites: Part A, Vol.41, (2010), pp.596-603.

(24) Islam, M.S., Pickering, K.L. and Foreman, N.J., Influence of accelerated ageing on the physico-mechanical properties of alkali-treated industrial hemp fibre reinforced poly(lactic acid)(PLA) composites, Polymer Degradation and Stability, Vol.95, (2010), pp.59-65.

(25) Sawpan, M.A., Pickering, K.L. and Fernyhough, A., Improvement of mechanical performance of industrial hemp fibre reinforced polylactide biocomposites, Composites: Part A, Vol.42, (2011), pp.310-319.

(26) Sawpan, M.A., Pickering, K.L. and Fernyhough, A.,Influence of loading rate, alkali fibre treatment and crystallinity on fracture toughness of random short hemp fibre reinforced polylactide bio-composites, Composites: Part A,Vol.42, (2011), pp.1148-1156.

(27) Plackett, D., Andersen, T.L., Pedersen, W.B. and Nielsen, L., Biodegradable composites based on L-polylactide and jute fibres, Composites Science and Technology, Vol.63, 
(2003), pp.1287-1296

(28) Khondker, O.A., Ishiaku, U.S., Nakai, A. and Hamada, H., A novel processing technique for thermoplastic manufacturing of unidirectional composites reinforced with jute yarns, Composites: Part A, Vol.37, (2006), pp.2274-2284.

(29) Ma, H. and Joo, C.W., Structure and mechanical properties of jute-polylactic acid biodegradable composites, Journal of Composite Materials, Vol.45, (2011), pp.1451-1460.

(30) Bledzki, A.K., Jaszkiewicz, A. and Scherzer, D., Mechanical properties of PLA composites with man-made cellulose and abaca fibres, Composites: Part A, Vol.40, (2009), pp.404-412.

(31) Iovino, R., Zullo, R., Rao, M.A., Cassar, L. and Gianfreda, L., Biodegradation of poly(lactic acid)/starch/coir biocomposites under controlled composting conditions, Polymer Degradation and Stability, Vol.93, (2008), pp.147-157.

(32) Kimura, T., Kurata, M., Matsuo, T., Matsubara, H. and Sakobe, T., Compression molding and mechanical properties of green-composite based on ramie/PLA non-twisted commingled yarn, Journal of the Society of Materials Science, Japan, Vol.53, No.7, (2004), pp.776-781, (in Japanese).

(33) Yu, T., Ren, J., Li, S., Yuan, H. and Li, Y., Effect of fiber surface-treatments on the properties of poly(lactic acid)/ramie composites, Composites: Part A, Vol.41, (2010), pp.499-505.

(34) Lee, S.-H. and Wang, S., Biodegradable polymer/bamboo fiber biocomposite with bio-based coupling agent, Composites: Part A, Vol.37, (2006), pp.80-91.

(35) Tokoro, R., Vu, D.M., Okubo, K., Tanaka, T., Fujii, T. and Fujiura, T., How to improve mechanical properties of polylactic acid with bamboo fibers, Journal of Materials Science, Vol.43, (2008), pp.775-787.

(36) Okubo, K., Fujii, T. and Thostenson, E.T., Multi-scale hybrid biocomposite: processing and mechanical characterization of bamboo fiber reinforced PLA with microfibrillated cellulose, Composites: Part A, Vol.40, (2009), pp.469-475.

(37) Cho, D., Seo, J.M., Lee, H.S., Cho, C.W., Han, S.O. and Park, W.H., Property improvement of natural fiber-reinforced green composites by water treatment, Advanced Composite Materials, Vol.16, (2007), pp.299-314.

(38) Graupner, N., Application of lignin as natural adhesion promoter in cotton fibre-reinforced poly(lactic acid) (PLA) composites, Journal of Materials Science, Vol.43, (2008), pp.5222-5229.

(39) Sellers, T. and Reichert, N.A., editors, Kenaf Properties, Processing \& Products, (1999), Mississippi State University.

(40) Suzuki, K., Research report on test growing and fiber extraction of kenaf, Report of Chiba Institute of Technology, No.51, (2004), pp.145-152.

(41) Kaldor, A. F., Kenaf, an fiber for the pulp and paper industries in developing and developed countries, TAPPI Journal, Vol.10, (1992), pp.141-145.

(42) Kaldor, A. F. and Hodges, C. W., Economics of introducing kenaf fibers as a complementary fiber source in existing wood pulp mills, in Proc. 1998 Pulping Conference, TAPPI, (1998).

(43) Suzuki, K., Kimpara, I., Saitoh, H. and Funami, K., Cross-sectional area measurement and monofilament strength test of kenaf bast fibers, Journal of the Society of Materials Science, Japan, Vol.54, No.8, (2005), pp.887-894, (in Japanese).

(44) Suzuki, K., A finite element modeling proposal for elucidating the tensile strength characteristics typically observed in natural plant fibers, Journal of Solid Mechanics and Materials Engineering, Vol.5, No.11, (2011), pp.573-588.

(45) Ramaswamy, G.N., Sellers, T., Tao, W. and Crook, Le G., Kenaf nonwovens as substrates for laminations, Industrial Crops and Products, Vol.17, (2003), pp.1-8.

(46) Onishi, K., Umeoka, K., Ando, H. and Liu, W., Development of kenaf boards and their properties, MEW Technical Report, No.80, (2003), pp.58-63, (in Japanese).

(47) Nishimura, T., Development of the car components using kenaf and a new evolution in biomaterials, Cellulose Communications, Vol.11, No.1, (2004), pp.29-34, (in Japanese).

(48) Zampaloni, M., Pourboghrat, F., Yankovich, S.A., Rodgers, B.N., Moore, J., Drzal, L.T., Mohanty, A.K. and Misra, M., Kenaf natural fiber reinforced polypropylene composites: A discussion on manufacturing problems and solutions, Composites: Part A, Vol.38, (2007), pp.1569-1580. 
(49) John, M.J., Bellmann, C. and Anandjiwala, R.D., Kenaf-polypropylene composite: Effect of amphiphilic coupling agent on surface properties of fibers and composites, Carbohydrate Polymers, Vol.82, (2010), pp.549-554.

(50) Shibata, S., Cao, Y. and Fukumoto, I., Lightweight laminate composites made from kenaf and polypropylene fibers, Polymer Testing, Vol.25, (2006), pp.142-148.

(51) Aji, I.S., Sapuan, S.M., Zainudin, E.S. and Abdan, K., Kenaf fibers as reinforcement for polymeric compoisites: A review, International Journal of Machanical and Materials Engineering, Vol.4, No.3, (2009), pp.239-248.

(52) Akil, H.M., Omar, M.F., Mazuki, A.A.M., Safiee, S., Ishak, Z.A.M. and Abu Bakar, A., Kenaf fiber reinforced composites: A review, Materials and Design, Vol.32, (2011), pp.4107-4121.

(53) Arai, S., Recent topics on kenaf in Thailand, THE GLOBE News, No.100, (2012), (in Japanese).

(54) Nishino, T., Hirano, K., Kotera, M., Nakamae, K. and Inagaki, H., Kenaf reinforced biodegradable composite, Composites Science and Technology, Vol.63, (2003), pp.1281-1286.

(55) Nishino, T., Hirano, K. and Kotera, M., X-ray diffraction studies on stress transfer of kenaf reinforced poly(L-lactic acid) composite, Composites: Part A, Vol.37, (2006), pp.2269-2273.

(56) Serizawa, S., Inoue, K. and Iji, M., Kenaf-fiber-reinforced poly(lactic acid) used for electric products, Journal of Applied Polymer Science, Vol.100, (2006), pp.618-624.

(57) Pan, P., Zhu, B., Kai, W., Serizawa, S., Iji, M. and Inoue, Y., Crystallization behavior and mechanical properties of bio-based green composites based on poly(L-lactide) and kenaf fiber, Journal of Applied Polymer Science, Vol.105, (2007), pp.1511-1520.

(58) Anuar, H., Zuraida, A., Kovacs, J.G. and Tabi, T., Improvement of mechanical properties of injection-molded polylactic acid-kenaf fiber biocomposite, Journal of Thermoplastic Composite Materials, Vol.25, (2012), pp.153-164.

(59) Saito, H., Hirata, Y., Suzuki, K. and Kimpara, I., A study for molding and mechanical property of long fiber kenaf/emulsion PLA composite, in Proc. 33rd FRP Symposium, Society of Materials Science, Japan, (2005), (in Japanese).

(60) Ochi, S., Mechanical properties of kenaf fibers and kenaf/PLA composites, Mechanics of Materials, Vol.40, (2008), pp.446-452.

(61) Ben, G., Kihara, Y., Nakamori, K. and Aoki, Y., Examination of heat resistant tensile properties and molding conditions of green composites composed of kenaf fibers and PLA resin, Advanced Composite Materials, Vol.16, (2007), pp.361-376.

(62) Huda, M.S., Drzal, L.T., Mohanty, A.K. and Misra, M., Effect of fiber surface-treatments on the properties of laminated biocomposites form poly(lactic acid)(PLA) and kenaf fibers, Composites Science and Technology, Vol.68, (2008), pp.424-432.

(63) Lee, B.-H., Kim, H.- S., Lee, S., Kim, H.-J. and Dorgan, J.R., Bio-composites of kenaf fibers in polylactide: Role of improved interfacial adhesion in the carding process, Composites Science and Technology, Vol.69, (2009), pp.2573-2579.

(64) Osawa, I., On processing and mechanical properties improvement of kenaf/PLA composites, In Proceedings of $23^{\text {rd }}$ Technical Symposium, School of Engineering, The University of Tokyo, (2008), pp.55-58, (in Japanese).

(65) Avella, M., Bogoeva-Gaceva, G., Buzarovska, A., Errico, M.E., Gentile, G. and Grozdanov, A., Poly(lactic acid)-based biocomposites reinforced with kenaf fibers, Journal of Applied Polymer Science, Vol.108, (2008), pp.3542-3551.

(66) Ogbomo, S.M., Chapman, K., Webber, C., Bledsoe, R. and D'Souza, N.A., Benefits of low kenaf loading in biobased composites of poly(L-lactide) and kenaf fiber, Journal of Applied Polymer Science, Vol.112, (2009), pp.1294-1301.

(67) Bos, H.L., Van Den Oever, M.J.A. and Peters, O.C.J.J., Tensile and compressive properties of flax fibres for natural fibre reinforced composites, Journal of Materials Science, Vol.37, (2002), pp.1683-1692.

(68) Baley, C., Analysis of the flax fibres tensile behaviour and analysis of the tensile stiffness increase, Composites: Part A, Vol.33, (2002), pp.939-948.

(69) Goda, K., Sreekala, M.S., Gomes, A., Kaji, T. and Ohgi, J., Improvement of plant based natural fibers for toughening green composites - Effect of load application during mercerization of ramie fibers, Composites: Part A, Vol.37, (2006), pp.2213-2220. 